\title{
Safe pregnancy and delivery in COVID-19 time
}

\author{
Sakshi Agarwal* \\ Department of Obstetrics and Gynecology, Heritage Institute of Medical Sciences, Varanasi, Uttar Pradesh, India
}

Received: 06 July 2020

Accepted: 27 July 2020

\section{*Correspondence:}

Dr. Sakshi Agarwal,

E-mail: sakshi.grmc@gmail.com

Copyright: () the author(s), publisher and licensee Medip Academy. This is an open-access article distributed under the terms of the Creative Commons Attribution Non-Commercial License, which permits unrestricted non-commercial use, distribution, and reproduction in any medium, provided the original work is properly cited.

\begin{abstract}
The impact of COVID-19 on pregnant women is yet not defined. There is no clear evidence that they are more susceptible to COVID-19. Clinical features and diagnostic workup are similar as in non-pregnant women. This virus has been reported to cause complications like premature rupture of membranes, preterm birth and fetal distress in the last trimester but effects in first and second trimester are not apparent. This infection is a supportive indication for delivery if pregnant patient requires improvement in oxygen saturation. Treating doctor has to make individualized decision regarding mode of delivery considering maternal and fetal clinical conditions. Its vertical transmission from mother to baby and presence in breast milk and vaginal secretions has not been reported. So mother can feed breast milk to babies or it can be given in form of expressed milk. Further research and data collection are required for unanswered questions.
\end{abstract}

Keywords: Coronavirus, COVID-19, Delivery, Pregnancy

\section{INTRODUCTION}

At present novel coronavirus disease (COVID-19) is a biggest public health emergency worldwide. In December 2019, its first case was reported in Wuhan, China. At present this infection has involved almost all countries of the world including India. World Health Organization (WHO) declared this as a pandemic on $11^{\text {th }}$ March 2020. There are various challenges in front of physicians and surgeons in managing their patients in COVID time. Similarly, in obstetrics and gynecological practices, this infection can have impact on pregnant women, their fetuses and neonatal outcome. ${ }^{1,2}$ To manage antenatal phase, having safe vaginal delivery or caesarean section, and postnatal care to neonate are important areas need to be discussed and management in the context of COVID19 poses a challenge. In this review, we will discuss symptoms and diagnostic work up, follow-up antenatal visits, mode of delivery, vertical transmission and safe obstetric practices in COVID time.

\section{CLINICAL FEATURES}

Pregnant women do not appear more likely to contract the infection than the general population. But pregnancy is a physiological state that predisposes women to viral infection as they have changes in their immune and cardiopulmonary systems. They can develop severe symptoms after infection with respiratory viruses. In 2009 , influenza A subtype H1N1 infected $1 \%$ of pregnant women but that caused approximate $5 \%$ of all H1N1related mortality. ${ }^{1}$ In other type of corona viruses like severe acute respiratory syndrome coronavirus (SARS$\mathrm{CoV}$ ) and middle east respiratory syndrome coronavirus (MERS-CoV), risk to mother and complications appears to be high like need for endotracheal intubation, ICU admission, kidney failure and death, premature rupture of membranes, fetal distress, preterm birth etc. especially in third trimester. ${ }^{2,3}$ Interestingly, COVID-19 infection has milder impact on pregnant women. Other symptoms are similar to in non-pregnant women like fever, cold, cough, 
myalgia, malaise, sore throat, diarrhoea and shortness of breath. ${ }^{4}$

\section{DIAGNOSTIC WORKUP}

The exact diagnosis of COVID-19 is usually based on epidemiological exposure, clinical features, routine laboratory investigations results, findings on computed tomography (CT) of the chest and a positive result of respiratory tract specimen by quantitative reverse transcription polymerase chain reaction (qRT-PCR). Transmission occurs mainly by respiratory droplets, but alternative faecal-oral route also has some evidences in the literature. ${ }^{5-7}$ Most of the patients may have lymphopenia and increased C-reactive protein on blood investigations. Chest CT scans can have multiple patchy ground-glass shadows in the lungs. As Yang et al. stated, all these methods are simultaneously useful but can have limitations. Even RT-PCR has a 30\% false-negative rate. So, to make definitive diagnosis it should include elaborate and detailed history along with investigations. They recommended TOCC scheme: travel, occupation, contact and cluster history collection. ${ }^{8-11}$

\section{ANTENATAL VISITS}

Pregnant women in particular are encouraged to take all measures to optimize their health and avoid getting exposure to COVID-19. All women should visit doctor at least 3 times and have Ultrasound (USG) between 11 to 14 weeks in first trimester, 20 to 25 weeks in second trimester and 30 to 35 weeks in third trimester. In case of high-risk pregnancies USG and consultation visits can be increased to monthly or twice monthly as a follow-up protocol. Second consultation can be as remote consultation by telemedicine services. Women in third trimester are considered to be at high risk of developing a severe form of COVID-19. So, all safety precautions including face mask and social distancing must be followed. ${ }^{12}$

\section{DELIVERY}

Normal vaginal delivery should be continued if the onset of labor is spontaneous and progressing well, but the second stage should be shortened to avoid active pushing. Yang et al had doubts whether COVID-19 positive women should deliver vaginally, due to the risk of infection transmission to new-born as well as to physicians and health care workers as labor is a prolonged process. The COVID-19 infection itself should not be an indication for delivery, unless it is necessary to improve maternal poor oxygenation. In literature, vaginal secretions have not shown positivity for virus. Decisions should be individualized, considering maternal and fetal clinical conditions. ${ }^{13}$ Obstetricians noticed COVID-19 pneumonia as a co-indication for surgical delivery. ${ }^{14}$

Both patients and healthcare workers should follow guidelines to prevent getting infections from each other.
Pregnant patients should be preferred to treat in hospital with tertiary care setting, with isolation of suspected cases. There should be availability of negative-pressure isolation rooms for COVID-19 confirmed cases. Health care staff should always use personal protective equipment (PPE) including a respirator, goggle, face mask, face protective shield, surgical gown and gloves and use of hand sanitizer. Patient should also wear face mask. Proper disinfection and sterilization of instruments, monitoring devices and ultrasound equipment is mandatory before reuse. Obstetric emergency should be managed quickly with all preventive measures irrespective of COVID status if time do not permit for testing. ${ }^{14}$

\section{PERINATAL OUTCOME AND RISK OF VERTICAL TRANSMISSION}

Of major concern is whether the virus can be transmitted from mother to baby. Literature suggest that there is no risk of vertical transmission from mother to neonate or via breastfeeding. Neither this virus is teratogenic nor it cause miscarriages, congenital anomalies, fetal growth retardation and spontaneous preterm birth, when COVID19 infection is acquired during first or early second trimester of pregnancy.

\section{BREASTFEEDING}

Breast milk has not been found to contain COVID-19 virus so infected mothers still can maintain lactation. As this virus can spread from close contact, neonate can be kept away from mother if mother is suspicious or confirmed positive. The mothers are, however, advised to express breast milk in order to maintain milk production. After negative reports, they are then able to breastfeed their infant. In mildly symptomatic or asymptomatic cases breastfeeding can be continued with proper precautions like use of face mask and hand-washing. ${ }^{9,13}$

\section{PREVENTION AND TREATMENT}

Preventive measures include social distancing, use of face mask, gloves and personal protective equipment kits, hand-washing, testing at large scale and isolation and quarantine if required. There is yet no specific treatment or cure has been discovered for COVID-19. Though multiple new therapies are coming but mainly symptomatic treatments are used. This include antipyretics, antibiotics, anti-inflammatory agents, antiviral therapy, use of oxygen and ventilators in severe cases.

Though intra-partum care in labor is almost similar as routine pregnant women care in non COVID area with use of safety precautions. Few important steps need to be taken care of like regular monitoring of vitals, temperature, respiratory rate, oxygen saturations etc. Use of USG, doppler and cardiotocography should be promoted for electronic fetal monitoring. During labor 
oxygen saturation should be monitored on hourly basis and it is kept above 94\% level. In case of deterioration of mother's health during labor, make an individualized decision regarding continuing of labor or emergency caesarean section if this is likely to shorten the procedural time and assist in resuscitating the mother as well as shorten the exposure to surroundings. ${ }^{6,9,13}$

\section{CONCLUSION}

Pregnant women have similar risk of getting COVID-19 as others. Clinical features and diagnostic workup are similar as in non-pregnant women. This virus has been reported to cause complications like premature rupture of membranes, preterm birth and fetal distress in the last trimester but effects in first and second trimester are not apparent. Though pregnant women should take all preventive measures to prevent getting infection. There is no evidence of vertical transmission from mother to baby or presence of virus in breast milk. So, further research and data collection are necessary.

\section{Funding: No funding sources}

Conflict of interest: None declared

Ethical approval: Not required

\section{REFERENCES}

1. Siston AM, Rasmussen SA, Honein MA, Fry AM, Seib K, Callaghan WM, et al. PandemicH1N1 influenza in pregnancy working group. Pandemic 2009 influenza A (H1N1) virus illness among pregnant women in the United States. JAMA. 2010;303:1517-25.

2. Wong SF, Chow KM, Leung TN, Ng WF, Ng TK, Shek CC, et al. Pregnancy and perinatal outcomes of women with severe acute respiratory syndrome. Am J Obstet Gynecol. 2004;191:292-7.

3. Alfaraj SH, Al-Tawfiq JA, Memish ZA. Middle East respiratory syndrome coronavirus (MERS-CoV) infection during pregnancy: report of two cases and review of the literature. J Microbiol Immunol Infect. 2019;52:501-3.

4. Chen H, Guo J, Wang C, Luo F, Yu X, Zhang W, et al. Clinical characteristics and intrauterine vertical transmission potential of COVID-19 infection in nine pregnant women: a retrospective review of medical records. Lancet. 2020;395:809-15.
5. Wang L, Shi Y, Xiao T, Fu J, Feng X, Mu D, et al. Chinese expert consensus on the perinatal and neonatal management for the prevention and control of the 2019 novel coronavirus infection (first edition). Ann Transl Med. 2010;8:47.

6. Liu D, Li L, Wu X, Zheng D, Wang J, Liang B, et al. Pregnancy and perinatal outcomes of women with COVID-19 pneumonia: a preliminary analysis. Am J Roentgenol. 2020;215:127-32.

7. Wang X, Zhou Z, Zhang J, Zhu F, Tang Y, Shen X. A case of 2019 novel coronavirus in a pregnant woman with preterm delivery. Clin Infect Dis. 2020;71(15):844-6.

8. Schwartz DA, Graham AL. Potential maternal and infant outcomes from coronavirus 2019-nCoV (SARS-CoV-2) infecting pregnant women: lessons from SARS, MERS, and other human coronavirus infections. Viruses. 2020;12:194.

9. Yang H, Wang C, Poon LC. Opinion. Novel coronavirus infection and pregnancy. Ultrasound Obstet Gynecol. 2020;55:435-7.

10. Rasmussen SA, Smulian JC, Lednicky JA, Wen TS, Jamieson DJ. Coronavirus disease 2019 (COVID-19) and pregnancy: what obstetricians need to know. Am J Obstet Gynecol. 2020;222(5):415-26.

11. Jenco M. Experts discuss COVID-19 impact on children, pregnant women; AAP News. Available at: https://www.aappublications.org/ news/2020/03/12/ coronavirus031220. Accessed on $05^{\text {th }}$ May 2020.

12. Vivanti AJ, Deruelle P, Picone O, Guillaume S, Roze JC, Mulin B, et al. Follow-up for pregnant women during the COVID-19 pandemic: French national authority for health recommendations. J Gynecol Obstet Human Reprod. 2020:101804.

13. Poon LC, Yang H, Lee JC, Copel JA, Leung TY, Zhang Y, et al. ISUOG interim guidance on 2019 novel coronavirus infection during pregnancy and puerperium: information for healthcare professionals. Ultrasound Obstet Gynecol. 2020;55:700-8.

14. Chen H, Guo J, Wang C, Luo F, Yu X, Zhang W, et al. Clinical characteristics and intrauterine vertical transmission potential of COVID-19 infection in nine pregnant women: a retrospective review of medical records. Lancet. 2020;395:809-15.

Cite this article as: Agarwal S. Safe pregnancy and delivery in COVID-19 time. Int J Reprod Contracept Obstet Gynecol 2020;9:3919-21. 